\title{
Perancangan User Experience Menggunakan Metode Five Planes Pada Aplikasi Mobile Kode Funding Di PT Kodetag Global Teknotama
}

(User Experience Design with Five Planes Method on Kode Funding Mobile Application at PT Kodetag Global Teknotama)

\author{
Paramita Retno Utami ${ }^{1}$, Firman Ardiansyah ${ }^{2}$, Muhammad Zubair ${ }^{3}$ \\ ${ }^{1}$ Sekolah Vokasi Institut Pertanian Bogor, Jalan Kumbang 14, Bogor \\ 2 Fakultas Matematika dan IImu Pengetahuan Alam Institut Pertanian Bogor, Kampus IPB, Jalan \\ Meranti, Bogor \\ ${ }^{3}$ Kodetag Global Teknotama, Jalan Angsana 11, Bogor
}

Email : 1 paramitaretnow@gmail.com, ${ }^{2}$ firmanardiansyah@gmail.com, zubairmi45@gmail.com

\begin{abstract}
Kode Funding Application is a cooperative mobile-based application which is a service product of PT Kodetag Global Teknotama. This application is designed to have features of cooperatives transactions, but it has not been designed with user experience (UX) and user interface optimization (UI) to meet the needs and achieve user satisfaction. As the consequence, when the user used the application, they faced difficulties in making transactions on the application such as data input errors. These following things will affect the performance of the user while making the transactions.

The design of user experience and user interface optimization are designed to build an Android mobile application prototype for Koperasi Simpan Pinjam dan Pembiayaan Syariah (KSPPS) Kode Funding that is using the Five Planes Element of User Experience by Garrett (2011) and considering the aspects of usability and aesthetics. The evaluation was carried out using techniques such as think aloud and learnability assessment by testing 5 participants for a medium fidelity prototype. The final evaluation results on usability testing using task success get a $90 \%$ success rate for time and task completion. All participants can complete the proposed task. Meanwhile, the results of the time completion evaluation were calculated to be 5 out of 50 participants that exceeded the time limit. Participants assumed that the prototype with $U X$ design giving a more attractive appearance and the better experience when using the application, as well as the availability of detailed transaction information.
\end{abstract}

Keywords : Cooperative, Five planes, Garrett, Usability, User experience, User interface 


\begin{abstract}
ABSTRAK
Aplikasi Kode Funding adalah aplikasi koperasi berbasis mobile yang merupakan produk layanan dari PT Kodetag Global Teknotama. Aplikasi ini telah dirancang memiliki fungsi atau fitur transaksi pada koperasi, namun belum dilakukan perancangan user experience (UX) dan optimasi user interface (UI) untuk memenuhi kebutuhan dan mencapai kepuasan pengguna. Sehingga, ketika user menggunakan aplikasi tersebut, terdapat kesulitan dalam melakukan transaksi pada aplikasi seperti adanya kesalahan input data setoran. Hal berikut tentunya mempengaruhi performa dan kinerja dari pengguna aplikasi dalam bertransaksi.

Perancangan user experience dan optimasi user interface dimaksudkan agar terbentuknya prototipe aplikasi mobile Android Koperasi Simpan Pinjam dan Pembiayaan Syariah (KSPPS) Kode Funding yang menggunakan metode Five Planes User Experience Elements oleh Garrett (2011) dengan mempertimbangkan aspek usability dan estetika. Evaluasi dilakukan menggunakan teknik think aloud dan penilaian learnability dengan pengujian pada 5 partisipan untuk medium fidelity prototype. Hasil akhir evaluasi pada usability testing menggunakan task success mendapatkan success rate sebesar $90 \%$ untuk time and task completion. Seluruh partisipan dapat menyelesaikan task yang diajukan. Sedangkan, hasil evaluasi dari pemenuhan waktu terdapat 5 dari 50 partisipan melebihi batas waktu. Partisipan menganggap pengembangan prototipe dengan perancangan UX memberikan dampak tampilan yang lebih menarik dan pengalaman menggunakan aplikasi yang lebih baik, serta adanya informasi transaksi yang lebih rinci.

\section{Kata kunci : Five planes, Garrett, Koperasi, Usability, User experience, User interface}

\title{
PENDAHULUAN
}

PT Kodetag Global Teknotama merupakan sebuah perusahaan yang bergerak dalam bidang teknologi informasi. Perusahaan ini menyediakan jasa pembuatan, pengembangan produk dan layanan IT kepada klien. Salah satu layanan yang diberikan kepada klien adalah Kode Funding, aplikasi Koperasi Simpan Pinjam dan Pembiayaan Syariah (KSPPS) berbasis android. Aplikasi ini berfungsi untuk membantu karyawan di perusahaan klien dalam pendataan transaksi oleh anggota koperasi.

Dalam Undang-undang Perkoperasian No. 17 tahun 2012, Koperasi adalah badan hukum yang didirikan oleh orang perseorangan atau badan hukum koperasi, dengan pemisahan kekayaan para anggotanya sebagai modal untuk menjalankan usaha, yang memenuhi aspirasi dan kebutuhan bersama di bidang ekonomi, sosial, dan budaya sesuai dengan nilai dan prinsip koperasi. ${ }^{1}$

Aplikasi Kode Funding sendiri telah memiliki fungsi atau fitur transaksi pada koperasi, namun belum dilakukan perancangan user experience (UX) dan optimasi user interface (UI) untuk memenuhi kebutuhan dan mencapai kepuasan pengguna. Berdasarkan penilaian pihak stakeholder dan user terhadap aplikasi,

1 Undang-Undang Republik Indonesia Nomor 17 Tahun 2012 Tentang Perkoperasian, diakses dari http://www.peraturan.go.id/uu/nomor-17-tahun2012.html, pada 1 Mei 2019. 
pengguna mengalami kesulitan dalam memahami alur fungsi yang terdapat pada aplikasi. Sehingga, ketika user menggunakan aplikasi tersebut, terdapat kesulitan dalam melakukan transaksi seperti adanya kesalahan input data setoran. Kesalahan input data mengharuskan adanya penghapusan data transaksi yang salah oleh Branch Manager (BM). Hal berikut tentunya mempengaruhi dan memperlambat performa dan kinerja dari pengguna aplikasi dalam bertransaksi. Oleh karena itu, dibutuhkan solusi perancangan user experience pada aplikasi untuk memudahkan user dalam menggunakan aplikasi dan meningkatkan pengalaman pengguna.

Berdasarkan latar belakang permasalahan tersebut, maka penulis tertarik melakukan perancangan UX pada aplikasi mobile Kode Funding berfokus pada aspek usability dan optimasi UI yang mengacu pada design guidelines. Metode yang diterapkan adalah Five Planes User Experience Elements oleh Garrett (2011). Dengan menggunakan metode ini, dirancang medium fidelity prototype dari aplikasi dan dilakukan evaluasi menggunakan teknik think aloud dan penilaian learnability untuk mengetahui kualitas usability aplikasi. Usability dan utility membentuk usefullness (Nielsen 2012b). Dengan penilaian usability, dapat mengetahui seberapa mudah fitur aplikasi digunakan oleh pengguna dan utility dapat menggambarkan fitur yang dibutuhkan oleh pengguna.

Tujuan ingin dicapai adalah terbentuknya prototipe aplikasi mobile Android Koperasi Simpan Pinjam dan Pembiayaan Syariah (KSPPS) Kode Funding menggunakan metode Five Planes User Experience Elements dengan mempertimbangkan aspek usability dan estetika. Perancangan dilakukan untuk meningkatkan usability aplikasi berdasarkan kebutuhan pebisnis dan pengguna dalam melakukan transaksi pada koperasi.

\section{METODE PENELITIAN}

Pengembangan aplikasi ini menggunakan metode Five Planes User Experience Elements oleh Garrett (2011). Pada metode ini terdapat 5 tahapan (Gambar 1) yaitu strategy plane, scope plane, structure plane, skeleton plane, dan surface plane. Pengembangan dengan metode ini dilakukan secara bertahap dan setiap lapisan memiliki keterhubungan antara lapisan atas dengan bawahnya.

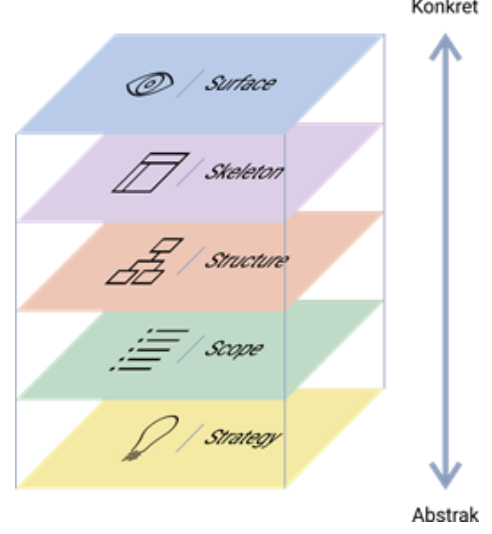

Gambar 1 Tahapan Five Planes User Experience Elements (Garrett 2011)

Dengan menggunakan metode ini, pengembangan aplikasi diawali dengan 
analisis kebutuhan pengguna dan tujuan bisnis pada strategy plane. Penentuan fitur dan spesifikasi fungsional dilakukan pada bagian scope plane. Pada structure plane, dilakukan perancangan interaksi pada aplikasi dan analisis task menggunakan Procedural Task Analysis (PTA). Tahap selanjutnya adalah skeleton plane meliputi perancangan paper prototype yang merupakan perwujudan desain interaksi meliputi layout dan penempatan elemen interaksi. Serta, pada surface plane merancang medium fidelity prototype berupa elemen visual yang mempertimbangkan aspek kontras, keseragaman, dan konsistensi dari pemilihan warna serta tipografi dengan memerhatikan design guidelines.

Evaluasi dilakukan menggunakan teknik think aloud dan penilaian learnability dengan pengujian pada 5 partisipan untuk medium fidelity prototype. Tahapan ini dilakukan untuk mengetahui kualitas usability aplikasi. Menurut Nielsen (1993), usability mempunyai beberapa komponen, yaitu learnability, efficiency, memorability, errors, dan satisfaction. Learnability adalah salah satu penilaian sehingga sistem yang dibuat dapat dipelajari dengan mudah dan pengguna dapat bekerja dengan cepat. Pada hasil akhir evaluasi akan tercapai penilaian success rate dan waktu task completion yang menggambarkan keberhasilan dari perancangan user experience pada aplikasi Kode Funding.

\section{HASIL DAN PEMBAHASAN}

\section{Tahap Strategy Plane}

Pada tahap strategy plane dilakukan observasi dan analisis terkait tujuan bisnis dari stakeholder (product objective), kebutuhan pengguna (user needs), dan perancangan persona (user persona). Hasil analisis tersebut sebagai berikut:

\section{Product Objective}

Product Objective didapatkan dengan melakukan survei dan wawancara kepada stakeholder secara langsung. Narasumber dalam wawancara tersebut adalah Bapak Muhammad Zubair selaku Direktur PT Kodetag Global Teknotama sekaligus pembimbing lapangan saat Praktik Kerja Lapangan (PKL). Kegiatan berikut dilakukan untuk mengetahui tujuan bisnis dan kebutuhan pengguna dari perancangan user experience aplikasi. Pihak perusahaan memiliki tujuan bisnis yaitu meningkatkan kepuasan pengguna sehingga dapat meningkatkan performa dalam bekerja menggunakan aplikasi Kode Funding.

Berdasarkan hasil wawancara yang telah dilakukan, pihak stakeholder menyetujui adanya perancangan UI dan UX pada aplikasi Kode Funding. Fungsi atau fitur yang memerlukan perancangan UI dan UX adalah fitur utama dari kegiatan bertransaksi dalam koperasi yaitu pembelian data, e-money, e-payment, transaksi menambah setoran, dan transaksi pada tabungan anggota. Kemudian, pihak stakeholder membutuhkan penambahan fitur seperti tampilan berita pada halaman utama aplikasi mobile.

\section{User Needs}

Untuk analisis kebutuhan pengguna dilakukan dengan survei berupa kuesioner atau Google Form yang disebarkan kepada anggota perusahaan klien yaitu Branch Manager dan Financial Advisor. Kuesioner berisi pertanyaan mengenai fungsi yang dibutuhkan oleh pengguna serta optimasi yang diinginkan 
untuk meningkatkan usability aplikasi. Dari survei yang telah dilakukan terdapat 7 partisipan yang semuanya berjenis kelamin laki-laki dengan bentang umur 19-39 tahun dan bekerja sebagai Financial Advisor (FA).

Penggunaan aplikasi Kode Funding didominasi oleh task tambah setoran sebanyak $71,4 \%$. Kejadian ini menunjukkan bahwa banyak pengguna menggunakan aplikasi Kode Funding untuk melakukan tambah setoran dan menambah rekening tabungan. Selengkapnya dapat dilihat pada Gambar 2.

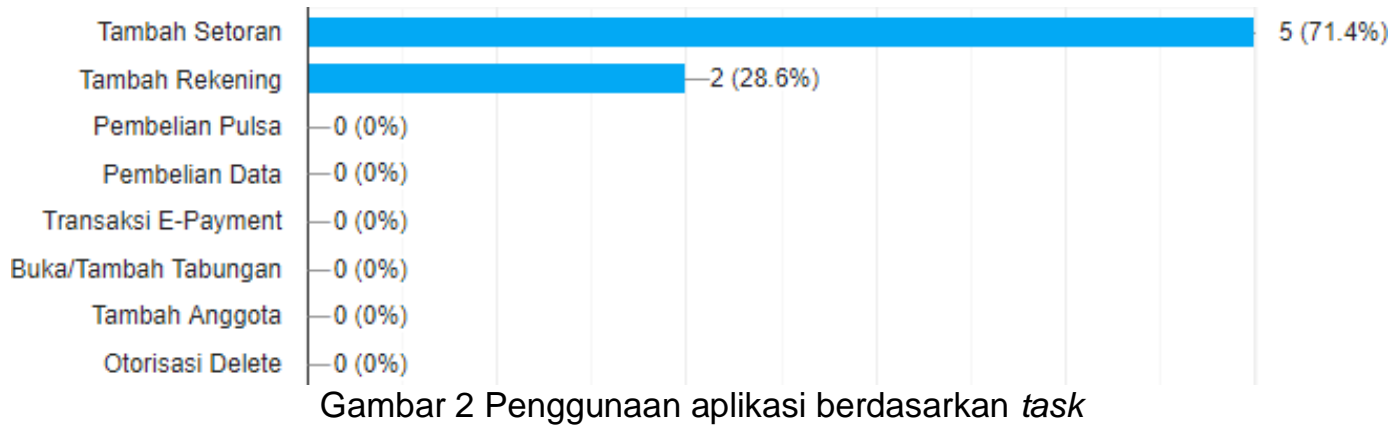

Selanjutnya, sebanyak $71,4 \%$ partisipan berpendapat bahwa sisi user interface dan sisi user experience aplikasi Kode Funding perlu ditingkatkan. Selengkapnya dapat dilihat pada Gambar 3.

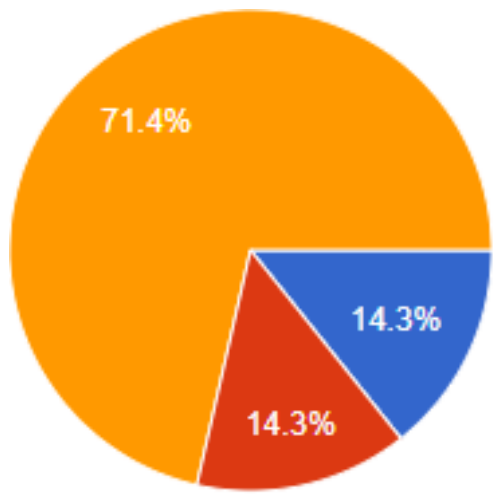

Tampilan / User Interface

Usability Fungsi / User Experience

Keduanya

Gambar 3 Kebutuhan peningkatan UI dan UX pada aplikasi Kode Funding

\section{User Persona}

Penentuan tokoh user persona dilakukan berdasarkan hasil analisis meliputi elemen-elemen pada kuesioner / kandidat persona dengan hasil isi kuesioner tertinggi atau persentase terbesar. Menurut Bowles (2011), penyusunan persona terdiri dari nama, foto, usia, pekerjaan, dan deskripsi singkat dari pengguna, sifat dan kebiasaan mereka. Tampilan user persona dapat dilihat pada Gambar 4. 

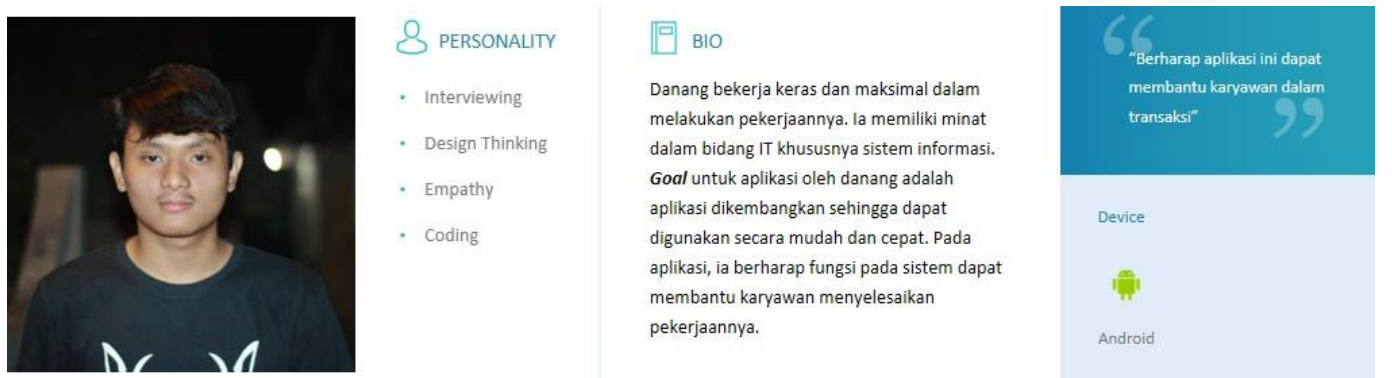

DANANG SAPRIYA

19 Tahun, Laki Laki

IT TECHNICAL SUPPORT

Berkah Bersama
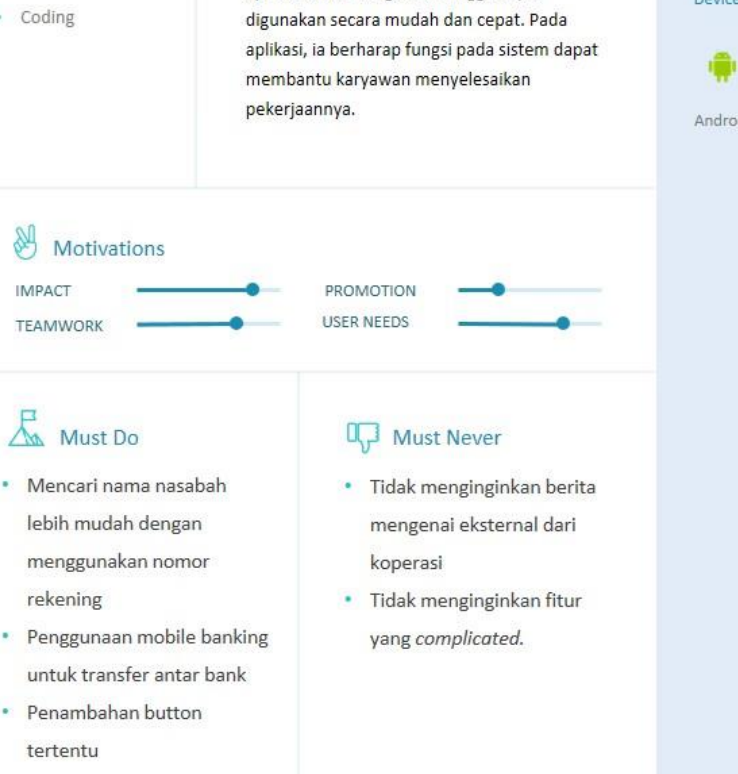

"1:

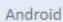

Gambar 4 User persona pengguna aplikasi Kode Funding

\section{Tahap Scope Plane}

Pada tahap scope plane menentukan device dan platform yang digunakan pada perancangan aplikasi, spesifikasi fungsionalitas dari fitur aplikasi, serta skenario pengguna yang sesuai dengan kebutuhan user dan tujuan bisnis.

\section{Device and Platform}

Perancangan prototype aplikasi mobile Kode Funding dikembangkan dengan menggunakan laptop yang memiliki spesifikasi Processor Intel Core i3, RAM 6GB, Harddisk 500GB. Alat masukan yang digunakan adalah keyboard fisik dan mouse. Sedangkan perangkat lunak yang digunakan yaitu Sistem Operasi Windows 10 Professional 64bit, Adobe Illustrator CS6, Adobe Photoshop CC 2017, dan untuk pembuatan medium fidelity prototype menggunakan Android Studio.

Perangkat mobile yang digunakan dalam melakukan pengujian yaitu Android Oreo dengan processor Octa-core $1.80 \mathrm{GHz}$, RAM 3GB dan layar 5.99 inci (1080 x 2160 piksel). Smartphone ini sesuai untuk digunakan pada pengujian perancangan UX aplikasi mobile Kode Funding.

\section{Spesifikasi Fungsionalitas}

Spesifikasi fungsionalitas adalah deskripsi cara kerja fungsi dan teknis dari sisi pengguna yang akan dirancang pada aplikasi Kode Funding. Fungsi ini dibentuk berdasarkan kebutuhan pengguna sehingga dapat memenuhi tujuan bisnis. Penentuan fungsi pada spesifikasi fungsionalitas didapat dari fungsi atau fitur yang sering digunakan pada aplikasi Kode Funding dan sesuai dengan kebutuhan pengguna yaitu fitur menambah setoran dan menambah rekening tabungan. Kemudian, berdasarkan kebutuhan bisnis dari stakeholder memerlukan 
adanya fitur pembelian data, pembelian e-money, pembelian e-payment, daftar transaksi, membuka tabungan, daftar anggota, daftar setoran, dan melihat berita pada aplikasi. Spesifikasi fungsionalitas aplikasi Kode Funding selengkapnya dapat dilihat pada Tabel 1.

Tabel 1 Spesifikasi fungsionalitas aplikasi Kode Funding

\begin{tabular}{|c|c|c|}
\hline No & Fungsi & Spesifikasi \\
\hline 1 & $\begin{array}{l}\text { Transaksi Pembelian } \\
\text { Data }\end{array}$ & $\begin{array}{l}\text { Aplikasi Kode Funding memungkinkan untuk } \\
\text { melakukan transaksi pembelian data dengan } \\
\text { metode pembayaran saldo anggota koperasi. }\end{array}$ \\
\hline 2 & $\begin{array}{l}\text { Transaksi Pembelian } \\
\text { E-Money }\end{array}$ & $\begin{array}{l}\text { Aplikasi Kode Funding memungkinkan untuk } \\
\text { melakukan transaksi pembelian E-Money } \\
\text { dengan metode pembayaran saldo milik } \\
\text { anggota koperasi. }\end{array}$ \\
\hline 3 & $\begin{array}{l}\text { Transaksi Pembelian } \\
\text { E-Payment }\end{array}$ & $\begin{array}{l}\text { Aplikasi Kode Funding memungkinkan untuk } \\
\text { melakukan transaksi e-payment dengan } \\
\text { metode pembayaran saldo milik anggota } \\
\text { koperasi. }\end{array}$ \\
\hline 4 & $\begin{array}{l}\text { Melihat Daftar } \\
\text { Transaksi }\end{array}$ & $\begin{array}{l}\text { Aplikasi Kode Funding dapat menampilkan } \\
\text { daftar dan rincian transaksi pembelian. }\end{array}$ \\
\hline 5 & Membuka Tabungan & $\begin{array}{l}\text { Aplikasi Kode Funding memungkinkan } \\
\text { pengguna untuk membuka atau daftartabungan } \\
\text { anggota koperasi. }\end{array}$ \\
\hline 6 & $\begin{array}{l}\text { Menambah } \\
\text { Rekening Tabungan }\end{array}$ & $\begin{array}{l}\text { Aplikasi Kode Funding memungkinkan untuk } \\
\text { menambah rekening tabungan milik anggota } \\
\text { terdaftar. }\end{array}$ \\
\hline 7 & $\begin{array}{l}\text { Melihat Data } \\
\text { Anggota }\end{array}$ & $\begin{array}{l}\text { Aplikasi Kode Funding memungkinkan } \\
\text { pengguna untuk melihat data anggota koperasi } \\
\text { yang memiliki tabungan terdaftar. }\end{array}$ \\
\hline 8 & Menambah Setoran & $\begin{array}{l}\text { Aplikasi Kode Funding dapat menambah } \\
\text { setoran dengan input saldo milik anggota } \\
\text { koperasi terdaftar. }\end{array}$ \\
\hline 9 & $\begin{array}{l}\text { Melihat Daftar } \\
\text { Setoran }\end{array}$ & $\begin{array}{l}\text { Aplikasi Kode Funding memungkinkan } \\
\text { pengguna untuk melihat daftar dan rincian } \\
\text { setoran yang telah dilakukan. }\end{array}$ \\
\hline 10 & Melihat Berita & $\begin{array}{l}\text { Aplikasi Kode Funding dapat menampilkan } \\
\text { berita mengenai sistem, produk, dan layanan } \\
\text { Kode Funding. }\end{array}$ \\
\hline
\end{tabular}




\section{Skenario Pengguna}

Skenario pengguna dibuat sebagai cerita singkat yang merepresentasikan karakter persona. Isi skenario merupakan proses saat pengguna menggunakan aplikasi. Berikut adalah skenario yang dibuat berdasarkan karakter persona.

Danang adalah salah satu karyawan perusahaan yang setiap harinya memiliki tugas untuk melakukan berbagai transaksi seperti pembelian data. Danang memiliki pengalaman yang kurang menyenangkan dalam menggunakan aplikasi karena ia susah mencermati flow fungsi pada aplikasi. Contohnya adalah ketika ia ingin memilih nomor rekening pada tahapan pembayaran transaksi dan ketika melihat rincian/detil transaksi yang telah dilakukan.

Danang mulai membuka aplikasi mobile Kode Funding, kemudian ia dapat melakukan transaksi pembelian data pada aplikasi. Danang dapat mengetikkan nomor yang dituju dan memilih besaran paket data yang akan dibeli. Setelah itu, Danang memilih anggota koperasi yang akan membayar tagihan tersebut dengan mencari nama anggota di kolom searchbar. Danang memilih salah satu anggota koperasi dan pergi ke halaman detil pembayaran. Pada halaman detil pembayaran, Danang dapat melihat rincian transaksi seperti nomor telepon, besaran paket data, harga, dan nama anggota koperasi. Kemudian, ia memilih nomor rekening anggota koperasi dan melakukan checkout untuk pembayaran transaksi. Pada halaman checkout, Danang dapat melihat detil transaksi disertai dengan saldo awal dan saldo akhir milik anggota koperasi. Selanjutnya, Danang dapat melihat rincian transaksi yang telah ia lakukan pada halaman daftar transaksi.

Selain itu, Danang dapat mengakses fitur berita seputar koperasi dan aplikasi Kode Funding sesuai kategori atau judul berita yang diinginkan. Dengan demikian, Danang merasa senang ketika mengakses aplikasi Kode Funding untuk bertransaksi dengan flowyang jelas, user interface yang baik, dan fitur yang sesuai dengan kebutuhan. Sehingga, aplikasi Kode Funding dapat membantunya dalam melakukan pekerjaan secara cepat dan mudah.

\section{Tahap Structure Plane}

Perancangan interaksi pada aplikasi Kode Funding dilakukan dengan menggunakan Procedural Task Analysis (PTA). Dengan menggunakan PTA dapat menggambarkan alur yang dibutuhkan pengguna dalam menyelesaikan task. Gambar 5 adalah alur task utama aplikasi yaitu task menambah setorandan 


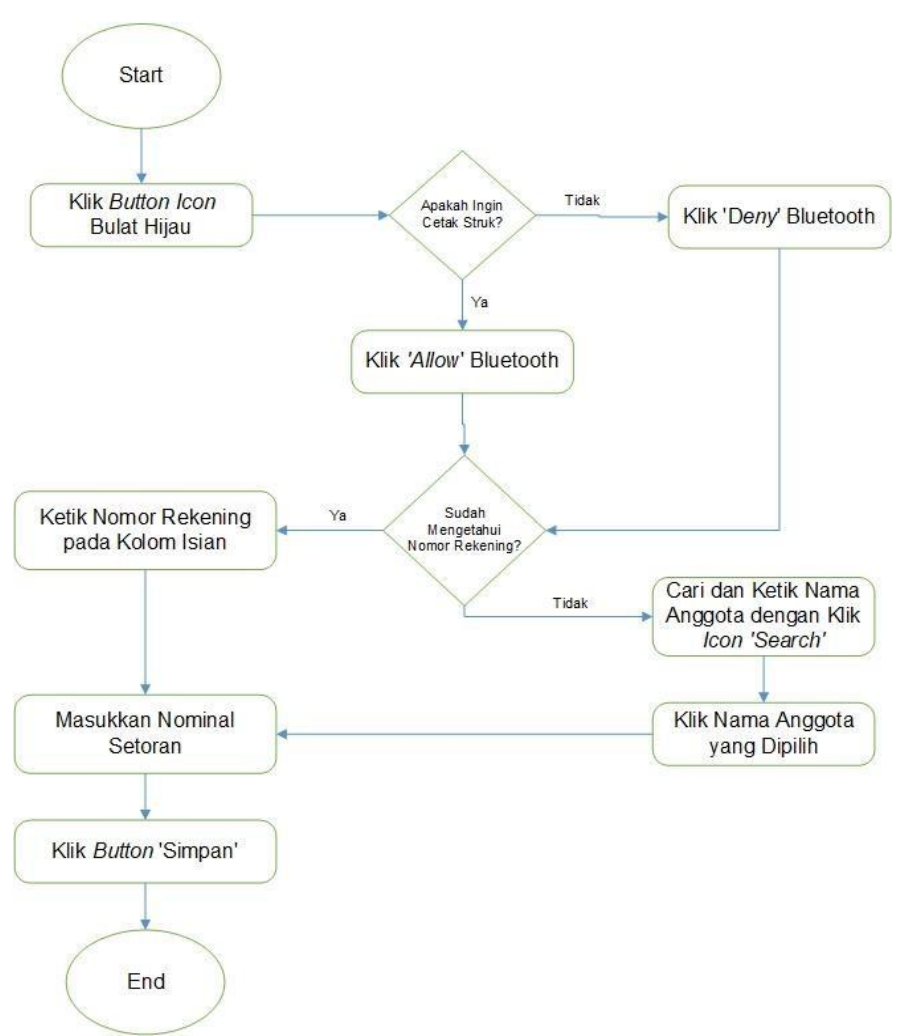

Gambar 5 Procedural Task Analysis pada task menambah setoran

\section{Tahap Skeleton Plane}

Perancangan layout pada tahap ini dilakukan dengan menggunakan teknik paper prototyping. Tahapan ini dilakukan dengan cara menggambar antarmuka semua task yang ada di aplikasi Kode Funding. Perancangan ini menggunakan peralatan sketch book, pensil, pulpen, spidol, dan drawing pen.

Pada tahap structure plane, pembuatan paper prototyping mengacu pada Procedural Task Analysis yang telah dibuat. Perancangan layout menu aplikasi Kode Funding mengacu pada navigasi tab menu untuk primary navigation dan navigasi springboard pada home screen untuk secondary navigation. Menurut Neil (2014), tab menu dan springboard masuk ke dalam primary navigation pattern kategori persistent untuk penempatan menu dengan kategori atau hirarki yang setara dan adanya kebutuhan quick access, serta kebutuhan akan adanya status indicators dari kategori menu yang ada. Ini menunjukkan bahwa penggunaan pattern tab menu dan springboard cocok untuk aplikasi Kode Funding karena kategori menu pada aplikasi memiliki kepentingan atau hirarki yang sama contohnya seperti transaksi tambah setoran dengan transaksi pembelian pulsa. Kemudian, dengan adanya kebutuhan pengguna untuk melihat menu atau informasi secara cepat (quick access), serta kebutuhan adanya status indicator contohnya untuk transaksi setoran yang diterima, ditolak, atau pending menunjukkan bahwa tab menu dan springboard pattern dapat diterapkan pada perancangan layout aplikasi Kode Funding. Tampilan tab menu dan springboard pada primary navigation patterns dapat dilihat pada Gambar 6 . 


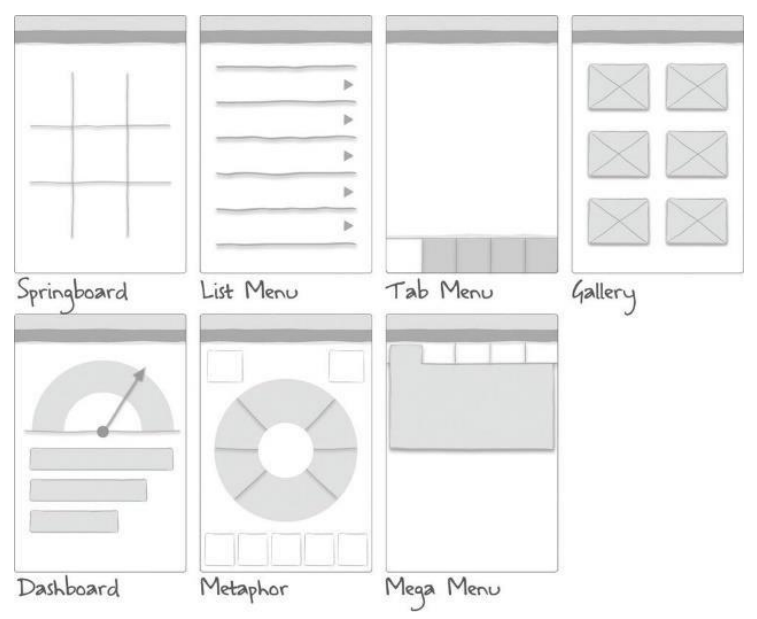

Gambar 6 Primary navigation patterns (Neil 2012)

Dengan penggunaan tab menu pada aplikasi Kode Funding, maka pengguna dapat melakukan navigasi dari satu kategori utama ke lainnya melalui akses langsung dari main screen. Selain itu, springboard pattern digunakan untuk layout menu pada home screen dan layout menu pada halaman transaksi PPOB. Hasil paper prototyping untuk halaman utama/beranda dengan tab menu dan springboard pattern dapat dilihat pada Gambar 7. Tampilan paper prototyping untuk halaman dari fitur utama aplikasi Kode Funding yaitu tambah setoran dapat dilihat pada Gambar 8.

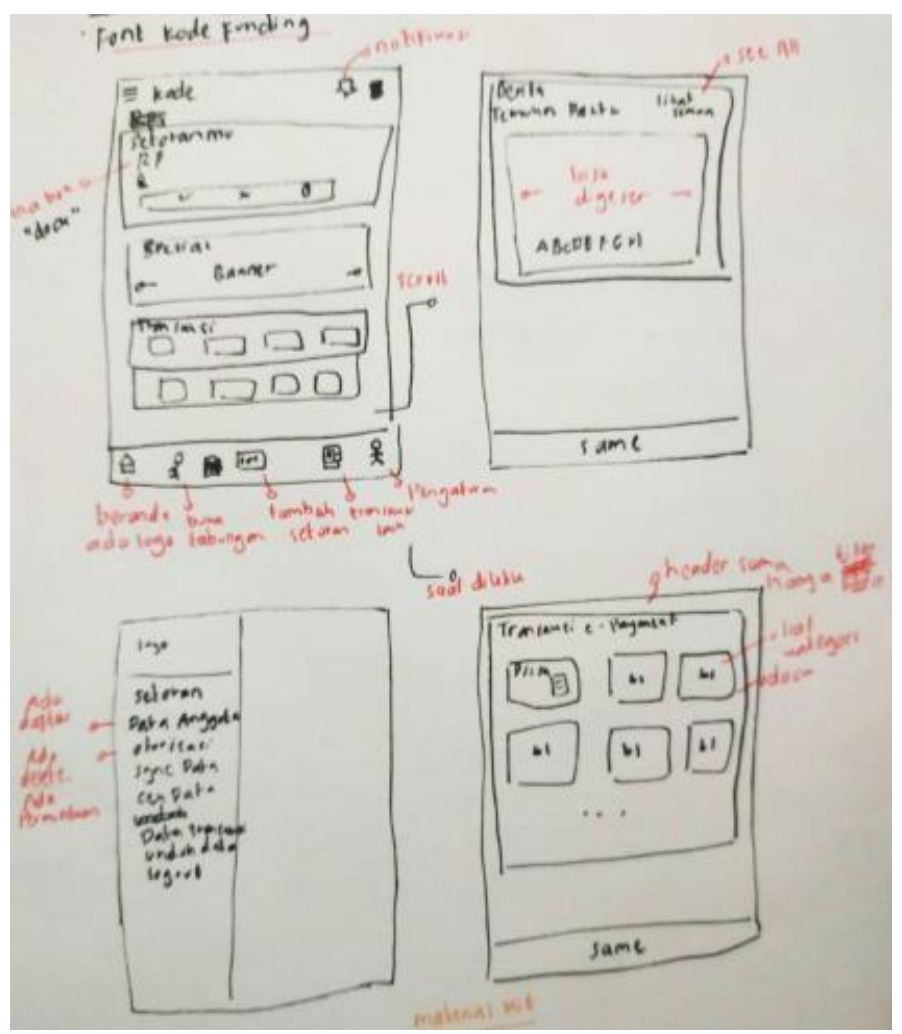

Gambar 7 Sketsa antarmuka halaman utama aplikasi dengan paper prototyping 


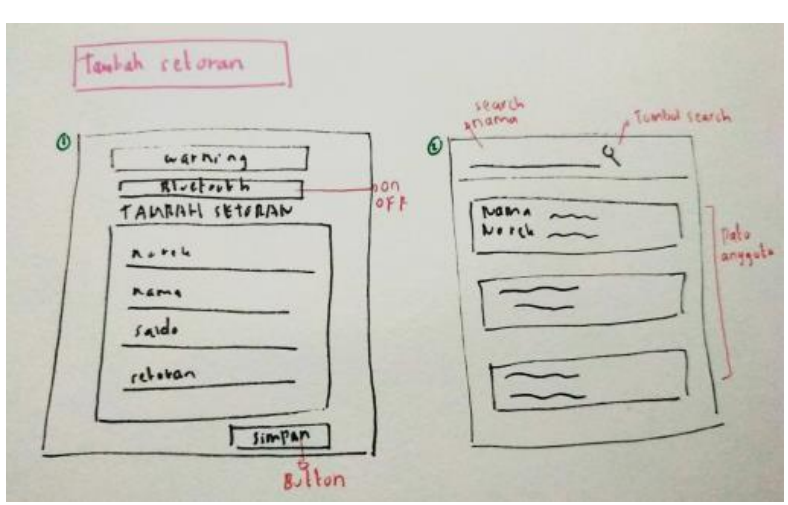

Gambar 8 Sketsa antarmuka halaman tambah setoran dengan paper prototyping

\section{Tahap Surface Plane}

Pada tahap surface plane dilakukan perancangan typography, color, navigation, dan components seperti button dan cards yang mengacu pada Google Material Design (2019). Selain itu, perancangan pada tahapan ini juga menggunakan guidelines dari aplikasi Kode Funding seperti penggunaan icon dan warna utama untuk aplikasi.

Dalam hal ini, perancangan layout mengacu pada paper prototyping pada tahap skeleton plane, sedangkan perancangan interaksi mengacu pada perancangan PTA dan analisis task pada tahap structure plane. Pemilihan typeface untuk typography menggunakan SF Pro Display dan pemilihan tersebut telah didiskusikan dengan stakeholder sebelumnya.

Untuk perancangan color theme atau color palette, mengacu pada Google Material Design berupa default color seperti primary color, secondary color, dan warna lainnya. Penggunaan tema warna dasar seperti ini dapat menentukan warna backgrounds, surfaces, error, tipografi, dan icon. Salah satu contohnya adalah pemilihan warna utama atau primary color yang sering ditampilkan pada aplikasi Kode Funding yaitu warna biru dan hijau. Warna ini merupakan branding dari aplikasi tersebut.

Kemudian, dilakukan perancangan tampilan cards mengacu pada Google Material Design (https://material.io) yang berguna untuk menampilkan konten atau informasi yang disajikan dalam bentuk teks atau gambar. Gambar 9 menunjukkan penggunaan cards pada Google Material Design.

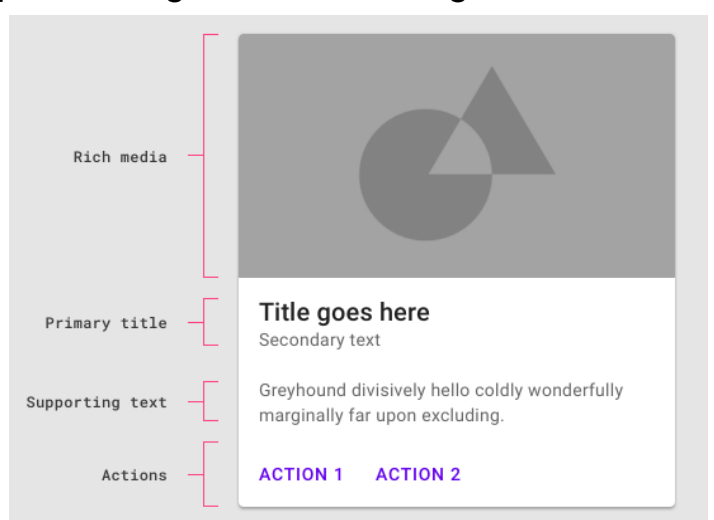

Gambar 9 Cards pada Google Material Design (Sumber: https://material.io) 
Mengacu pada Google Material Design (https://material.io), elemen pada cards dapat berupa rich media, primary title, supporting text, dan actions yang dapat menunjukkan hirarki. Dalam perancangan cards pada aplikasi Kode Funding digunakan elevated cards yang memiliki shadow atau elevation, serta menggunakan dividers berupa garis horizontal untuk membagi atau menunjukkan area tertentu dalam cards. Tampilan halaman rincian setoran dengan perancangan cards dapat dilihat pada Gambar 10.

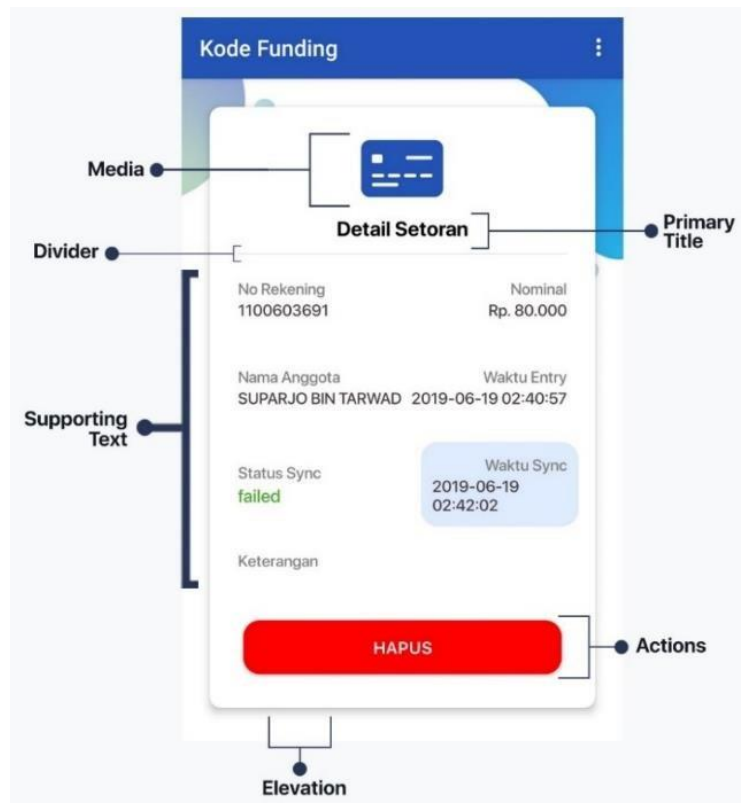

Gambar 10 Tampilan antarmuka rincian setoran dengan perancangan cards

Perancangan navigasi dilakukan pada home screen aplikasi Kode Funding dengan perancangan layout yaitu pattern tab menu dan springboards. Task utama dengan konsep tab menu diletakkan pada bagian bawah home screen. Task lainnya berdasarkan spesifikasi fungsionalitas dengan konsep springboards pattern diletakkan pada bagian atas home screen.

Pada medium fidelity prototype, juga dilakukan implementasi coding dengan menggunakan software Android Studio, sehingga interaksi fungsi pada prototype dapat dijalankan saat pengujian di tahap evaluasi.

\section{Tahap Evaluasi}

Pada tahap evaluasi berikut dilakukan pengujian aplikasi dengan teknik retrospective think aloud dan pengujian learnability menggunakan penghitungan task success. Evaluasi ini dilakukan untuk mengetahui usability aplikasi Kode Funding dan mengetahui feedback dari pengalaman yang dirasakan oleh pengguna saat menggunakan aplikasi. Menurut Nielsen (2000), pengujian pada 5 - 12 partisipan dapat mewakili dan menemukan masalah usability yang ada. Sehingga, dilakukan pengujian pada 5 dari 7 partisipan sebanyak 1 kali untuk medium fidelity prototype.

Pengujian aplikasi dilakukan dengan menyediakan beberapa task yang akan dikerjakan oleh tiap partisipan saat sesi pengujian. Task yang diuji kepada 
pengguna antara lain (a) transaksi pembelian data, (b) transaksi pembelian $e$ money, (c) transaksi pembelian e-payment, (d) melihat daftar transaksi, (e) membuka tabungan, (f) menambah rekening tabungan, $(\mathrm{g})$ melihat data anggota, (h) menambah setoran, (i) melihat daftar setoran, dan (j) melihat berita.

\section{Pengujian Medium Fidelity Prototype}

Evaluasi dilakukan dengan menjalani task yang ada dengan teknik think aloud dan penilaian learnability. Faktor penentu keberhasilan task ditentukan dari waktu tempuh yang tidak melewati batas waktu yang ditetapkan dalam menjalani suatu task. Batas waktu diperoleh dari hasil dry run yang dilakukan developerdan dikalikan 2 (Tullis 2013). Dengan menjalankan task yang ada, akan tercapai success rate untuk waktu dan task completion.

Berdasarkan data yang telah didapat, sebanyak 5 partisipan masing-masing menjalankan 10 task yang ada. Dengan menghitung jumlah partisipan dikalikan dengan jumlah task yang ada, maka total keseluruhan task berjumlah 50 task. Dalam hal ini, sebanyak 5 task dari total 50 task yang dilakukan oleh partisipan dinyatakan gagal karena melebihi batas waktu yang ditentukan. Kemudian, dengan menghitung keseluruhan jumlah task yang dikerjakan dibagi terhadap jumlah keseluruhan task, maka total nilai success rate sebesar 45/50 atau 90\%. Dari kesepuluh task yang telah diuji dibuatlah sebuah grafik task \& time completion. Grafik ini dapat menggambarkan pola partisipan dalam menyelesaikan task berdasarkan waktu yang telah ditentukan. Grafik persentase task \& time completion secara keseluruhan dapat dilihat pada Gambar 11.

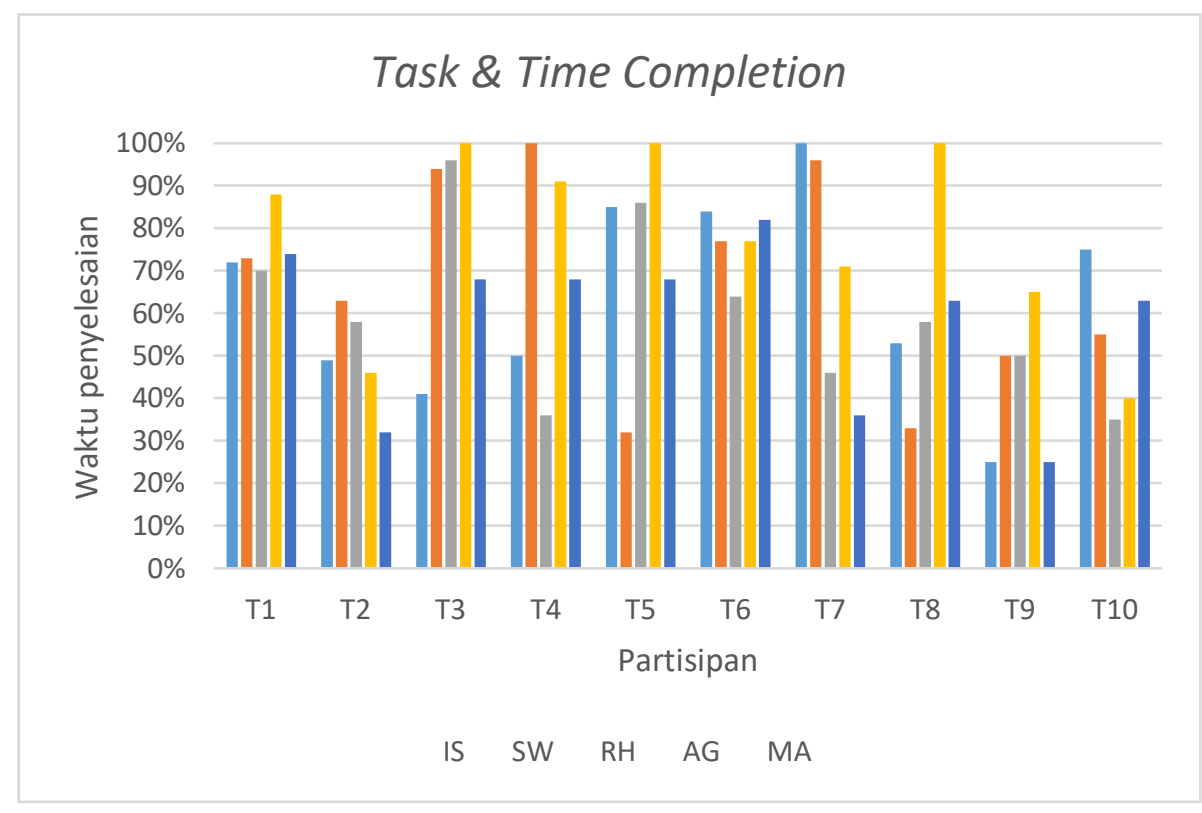

Gambar 11 Grafik persentase task \& time completion

Berdasarkan data yang telah didapat, partisipan menganggap bahwa task yang dijalankan memiliki tampilan yang baik dan menarik. Sebanyak 3 dari 5 partisipan menganggap bahwa task melihat daftar transaksi memiliki tampilan atau 
user interface yang baik. Pada task melihat daftar setoran, sebanyak 3 dari 5 partisipan berpendapat bahwa tampilan atau user interface pada task tersebut menarik.

Dengan menghitung hasil perbandingan rata-rata waktu penyelesaian task dengan waktu dry run developer dikalikan 100\%, maka akan menghasilkan efisiensi dari setiap task yang ada. Dari hasil perhitungan tersebut, task melihat daftar setoran memiliki efisiensi tertinggi yaitu sebesar 55\%. Diikuti oleh task pembelian e-money dengan efisiensi sebesar $50 \%$ dan task melihat berita dengan efisiensi sebesar $47.5 \%$. Dari perhitungan efisiensi task yang telah dilakukan, dibuatlah sebuah grafik efisiensi task yang dapat menggambarkan besarnya efisiensi setiap task yang ada. Grafik efisiensi task secara keseluruhan dapat dilihat pada Gambar 12.

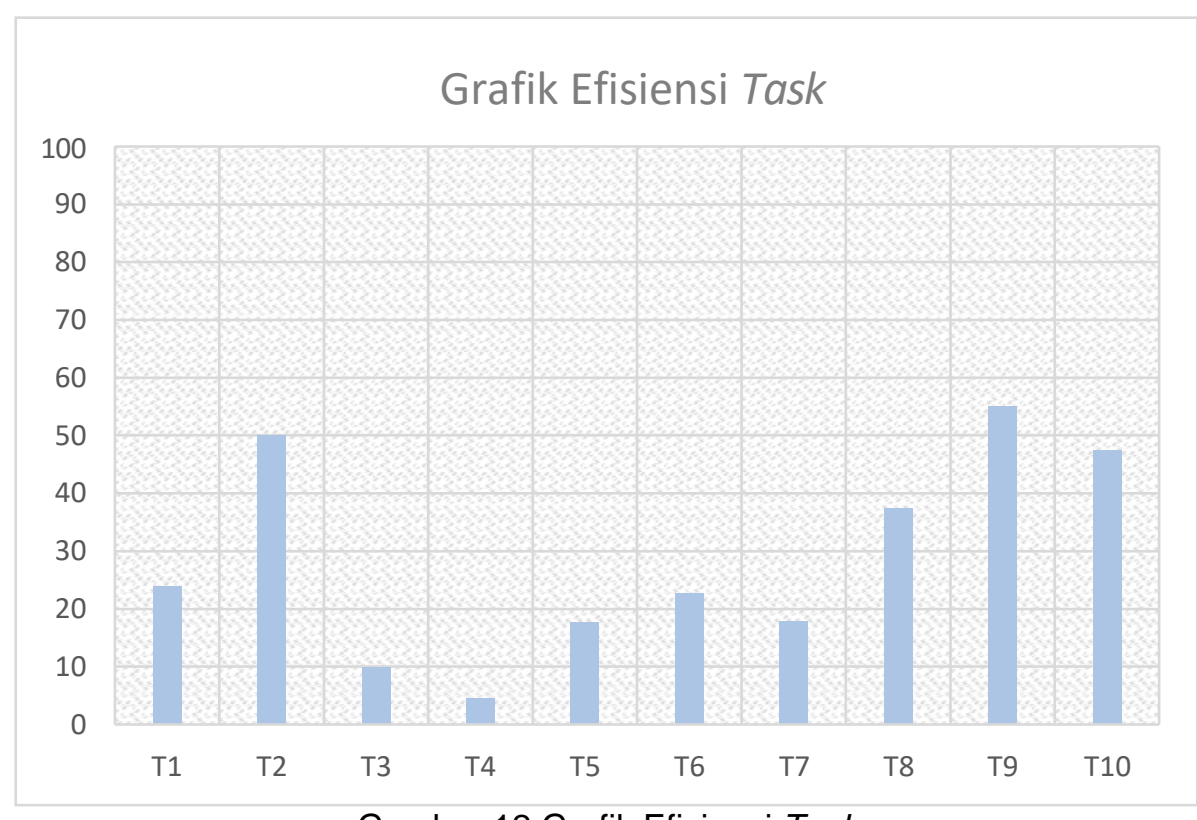

Gambar 12 Grafik Efisiensi Task

\section{SIMPULAN}

Prototipe aplikasi Kode Funding berhasil dibuat dengan merancang dan memerhatikan user experience yang sesuai kebutuhan pengguna dan tujuan bisnis para stakeholder. Perancangan user experience yang telah dibuat juga memerhatikan komponen usability dan estetika sehingga menciptakan alur fungsi sistem yang mudah dipahami oleh pengguna serta tampilan user interface yang menarik.

Hasil akhir evaluasi pada usability testing menggunakan task success mendapatkan success rate sebesar $90 \%$ untuk time and task completion. Seluruh partisipan dapat menyelesaikan task yang diajukan. Sedangkan, hasil evaluasi dari pemenuhan waktu terdapat 5 task dari total 50 task yang melebihi batas waktu. Partisipan menganggap pengembangan prototipe dengan perancangan UX memberikan dampak tampilan yang lebih menarik dan pengalaman menggunakan aplikasi yang lebih baik, serta adanya informasi transaksi yang lebih rinci. 


\section{SARAN}

Saran untuk Perancangan User Experience Menggunakan Metode Five Planes pada Aplikasi Mobile Kode Funding ini adalah prototipe sebaiknya dikembangkan hingga tingkat high fidelity prototype, sehingga partisipan dapat mengeksplorasi sistem secara keseluruhan dan tidak terikat dengan skenario pada saat usability testing. Analisis dari target pengguna aplikasi Kode Funding juga dapat dilakukan secara berkala agar menyesuaikan perubahan kebiasaan pengguna dan meningkatkan usability aplikasi sesuai kebutuhan. Hal berikut dapat dijadikan acuan perbaikan pada pengembangan prototipe selanjutnya.

\section{DAFTAR PUSTAKA}

Bowles, Cennydd, and James Box. 2011. Undercover User Experience Design. New York: New Riders Press.

Dabbagh N. 2014. Some Basic Differences Between a Procedural Task Analysis and a Hierarchical Analysis [internet]. [diunduh 2019 Juli 23]. Tersedia pada:http://cehdclass.gmu.edu/ndabbagh/Resources/IDKB/hierarchy_vs_ procedural.htm/.

Garrett JJ. 2011. The Elements of User Experience: User-Centered Design for the Web and Beyond, Ed ke-2. Berkeley (US): New Riders.

Haak, Maaike J. van den, Jong, Menno D. T. De, Schellens, Peter Jan. 2003. Retrospective vs. concurrent think-aloud protocols: testing the usability of an online lib. In Behaviour and Information Technology, 22 (5) pp. 339-351.

Neil T. 2012. Mobile Design Pattern Gallery, Color Edition: Chapter 1: Navigation [internet]. [diunduhn2019 Juli 23]. Tersedia pada:

https://www.oreilly.com/library/view/mobile-design-pattern/978144933645 5/ch01.html.

Neil T. 2014. Mobile Design Pattern Gallery: UI Patterns for Smartphone Apps. Ed ke-2. Sebastopol (US): O'Reilly Media.

Nielsen J. 1993. Usability engineering. San Francisco (CA): Morgan Kaufmann. Nielsen J. 2000. Why You Only Need to Test with 5 Users [internet]. [diunduh 2019

Juni 2]. Tersedia pada: https://www.nngroup.com/articles/why-you-only- need-totest-with-5-users/.

Nielsen J. 2012a. Thinking Aloud: The \#1 Usability Tool [internet]. [diunduh 2019 Juni 2]. Tersedia pada: https://www.nngroup.com/articles/thinking-aloudthe-1-usability-tool/.

Nielsen J. 2012b. Usability 101: Introduction to Usability [internet]. [diunduh 2019 Mei 3]. Tersedia pada: https://www.nngroup.com/articles/usability-101introduction-to-usability/.

Tullis T, Albert B. 2013. Measuring the User Experience: Collecting, Analyzing, and Presenting Usability Metrics. Ed ke-2. Massachusetts (US): Elsevier. 